\title{
IMPLEMENTASI SISTEM OTENTIKASI PADA PENGGUNA JARINGAN HOTSPOT DI UNIVERSITAS KANJURUHAN MALANG GUNA MENINGKATKAN KEAMANAN JARINGAN KOMPUTER
}

\author{
Yusriel Ardian \\ Universitas Kanjuruhan Malang \\ Jl. S. Supriyadi 48 Malang. Telepon: (0341) 801488 \\ Email: acilnet@yahoo.com
}

\begin{abstract}
ABSTRAK: Semakin banyaknya aplikasi yang menggunakan client server baik desktop maupun WEB Application membuat setiap user harus memiliki banyak user id dan password yang harus dihapalkan, karena setiap aplikasi pasti membutuhkan otentikasi agar dapat memanfaatkan aplikasi tersebut dengan alasan keamanan. Selain itu perkembangan media jaringan juga semakin berkembang baik penggunaan kabel maupun nirkabel. Dari penjelasan diatas teknologi RADIUS sangatlah dibutuhkan dalam kasus yang telah dijelaskan diatas, karena dengan metode RADIUS ini memungkinkan seorang user cukup memiliki satu user id untuk mengakses ke beberapa aplikasi, baik desktop maupun WEB application. Metode RADIUS juga dapat diintregasikan terhadap media kabel dan nirkabel.
\end{abstract}

Kata kunci: Nirkabel, WEP, otentikasi, RADIUS, database, server, client

\begin{abstract}
The number of client server applications using both desktop and WEB Application makes every user must have a lot of user id and password that must be memorized, because each application must require authentication in order to utilize the application for security reasons. Besides the development of network media is also growing use of both wired and wireless. From the above explanation RADIUS technology is desperately needed in the case described above, since the RADIUS method allows a user simply has a userID for access to multiple applications, both desktop and WEB application. RADIUS can also integrated method of wired and wireless media.
\end{abstract}

Keywords: Wireless, WEP, authentication, RADIUS, database, server, client

\section{PENDAHULUAN}

Penggunaan jaringan saat ini pada umumnya tanpa adanya otentikasi pengguna. Dengan tanpa adanya otentikasi pengguna ini maka jaringan dapat diakses oleh siapa saja ketika pengguna bergabung dalam jaringan.

Untuk media transmisi menggunakan wireless access point otentikasi menggunakan Wired Equivalent Privacy (WEP). Key pada WEP harus dipasang pada tiap access point dan tiap client access point, sehingga merepotkan administrator karena harus mendatangi masing-masing client. Key WEP juga bersifat statik sehingga mudah diketahui dengan melihat komputer client yang lain. Sekarang sudah ada beberapa aplikasi yang bisa membaca key WEP sehingga pengguna yang tidak berhak bias masuk ke jaringan, yang bisa membahayakan sistem di dalamnya.

Otentikasi WEP hanya diberikan kepada jalur koneksi untuk staf, sedangkan jalur koneksi untuk mahasiswa (hostspot) yang menggunakan media transmisi wireless access point tanpa menggunakan otentikasi sehingga dapat diakses oleh siapa saja. Pada media transmisi kabel yang menggunakan HUB sebagai pemecah koneksi tidak menggunakan otentikasi, sehingga dengan menancapkan kabel kita bisa langsung terhubung ke jaringan. Oleh karena itu dalam penelitian ini dibuat sistem untuk otentikasi pengguna, baik yang menggunakan media transmisi kabel maupun nirkabel.

Tujuan penulisan adalah untuk:

1) Pengembangan manajemen sistem keamanan jaringan yang lebih baik

2) Mengintregasikan manajemen user untuk beberapa aplikasi

\section{TINJAUAN PUSTAKA}

\section{Jaringan Wireless}

Jaringan Wireless Local Area Network (WLAN) merupakan salah satu bentuk jaringan wireless. Jaringan WLAN adalah jaringan yang memungkinkan dua mesin atau lebih untuk berkomunikasi menggunakan protokol jaringan standar tetapi tanpa 
menggunakan media transmisi kabel. Media transmisi yang digunakan komunikasi pada jaringan WLAN adalah gelombang elektromagnetik yang dapat berupa sinar infra-merah (infrared, IR), gelombang mikro (microwave) atau gelombang radio (radio frequency, RF). Mode Jaringan WLAN, antara lain:

\section{Mode Ad-Hoc}

Mode Ad-hoc sering disebut sebagai jaringan peer to peer atau disebut juga jaringan point to point. Mode Ad-hoc memungkinkan hubungan antar komputer pada jaringan WLAN tanpa melalui suatu access point.

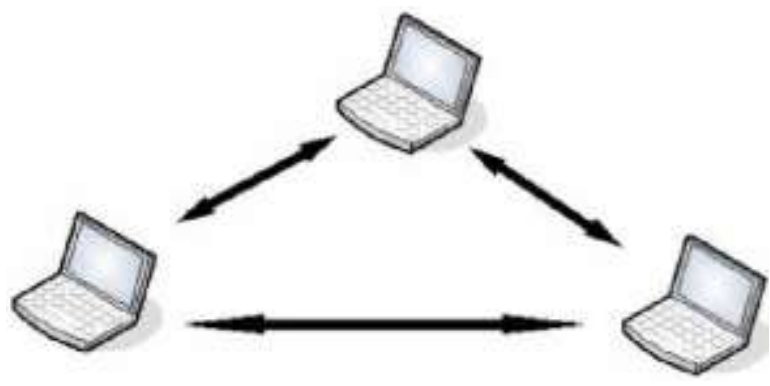

Gambar 1. Mode Ad-hoc

\section{Mode Infrastruktur}

Untuk menghubungkan banyak komputer jaringan WLAN harus dijalankan menggunakan mode Infrastruktur. Pada mode Infrastruktur diperlukan peralatan tambahan berupa wireless access point (WAP) atau disebut secara singkat dengan access point. Access point berlaku seperti HUB atau switch pada jaringan kabel, sehingga access point akan menjadi pusat dari jaringan WLAN

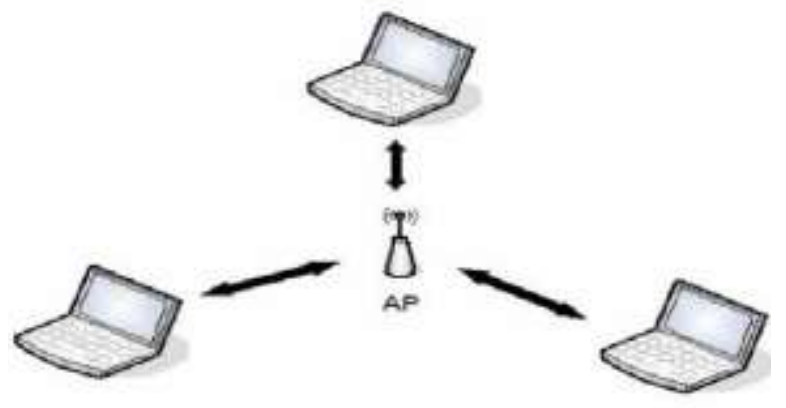

Gambar 2. Mode Infrastruktur

\section{Jaringan WLAN dan Ethernet}

Jaringan WLAN yang bekerja pada mode Infrastruktur dapat dihubungkan dengan jaringan lain misalnya jaringan Ethernet. Untuk berhubungan dengan jaringan lain diperlukan bridge. Access point yang beredar di pasaran umumnya sudah dapat difungsikan sebagai bridge.

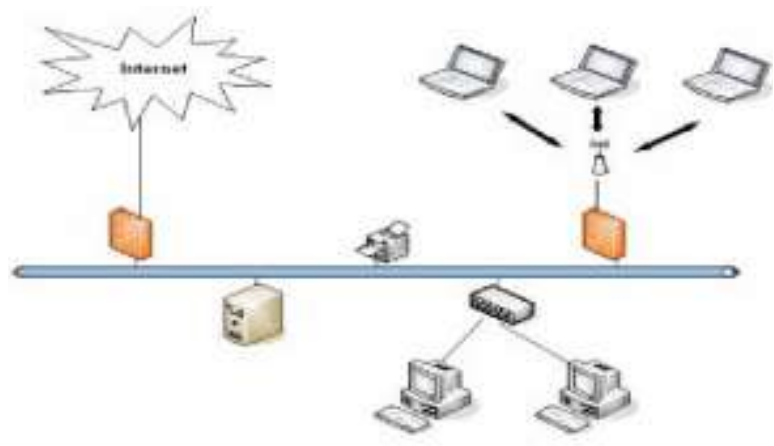

Gambar 3. Jaringan WLAN dan Ethernet

\section{Protokol Rute (Routing Protocol)}

Routing adalah proses membawa paket data dari satu host asal ke host tujuan melalui satu atau beberapa host node lainnya. Secara umum mekanisme koordinasi routing dapat dibagi menjadi dua, yaitu routing statis dan routing dinamis, dengan penjelasan sebagai berikut:

\section{Routing Statis}

Pada routing statis, entri-entri dalam forwarding tabel routing diisi dan dihapus secara manual sedangkan pada routing dinamis perubahan dilakukan melalui protokol routing. Routing statis adalah pengaturan routing paling sederhana yang dapat dilakukan pada jaringan komputer. Menggunakan routing statis murni dalam sebuah jaringan berarti mengisi setiap entri dalam forwarding table di setiap router yang berada dalam jaringan tersebut.

Penggunaan routing statis dalam sebuah jaringan yang kecil bukanlah sebuah masalah hanya beberapa entri yang perlu diisikan pada forwarding table di setiap router. Sebaliknya jika harus melengkapi forwarding table di setiap router yang jumlahnya tidak sedikit dalam jaringan yang besar.

\section{Routing Dinamis}

Routing dinamis adalah cara yang digunakan untuk melepaskan kewajiban mengisi entri-entri forwarding table secara manual. Protokol routing mengatur router-router sehingga dapat berkomunikasi satu dengan yang lain dan saling memberikan informasi routing yang dapat mengubah isi forwarding table, tergantung keadaan jaringannya. Dengan cara ini, router-router mengetahui keadaan jaringan yang terakhir dan mampu meneruskan datagram ke arah yang benar. 


\section{RADIUS (Remote Authentication Dial-In User Service)}

RADIUS adalah sebuah protokol keamanan komputer yang digunakan untuk melakukan otentikasi, otorisasi, dan pendaftaran akun pengguna secara terpusat untuk mengakses jaringan. RADIUS didefinisikan di dalam RFC 2865 dan RFC 2866, yang pada awalnya digunakan untuk melakukan otentikasi terhadap akses jaringan secara jarak jauh dengan menggunakan koneksi dial-up. RADIUS, kini telah diimplementasikan untuk melakukan otentikasi terhadap akses jaringan secara jarak jauh dengan menggunakan koneksi selain dial-up, seperti halnya VPN (Virtual Private Networking), access point nirkabel, switch Ethernet, dan perangkat lainnya.

Server RADIUS menyediakan mekanisme keamanan dengan menangani otentikasi dan otorisasi koneksi yang dilakukan pengguna. Pada saat computer client akan menghubungkan diri dengan jaringan maka server RADIUS akan meminta identitas pengguna (username dan password) untuk kemudian dicocokkan dengan data yang ada dalam database server RADIUS untuk kemudian ditentukan apakah pengguna diijinkan untuk menggunakan layanan dalam jaringan komputer. Jika proses otentikasi dan otorisasi berhasil maka proses pelaporan dilakukan, yakni dengan mencatat semua aktifitas koneksi pengguna, menghitung durasi waktu dan jumlah transfer data yang dilakukan oleh pengguna. Proses pelaporan yang dilakukan server RADIUS bisa dalam bentuk waktu (detik, menit, jam) maupun dalam bentuk besar transfer data (Byte, KByte, Mbyte).

\section{WEP}

WEP (Wired Equivalent Privacy) adalah suatu metode pengamanan jaringan nirkabel, disebut juga dengan Shared Key Authentication. Shared Key Authentication adalah metode otentikasi yang membutuhkan penggunaan WEP.

Enkripsi WEP menggunakan kunci yang dimasukkan (oleh administrator) ke client maupun access point. Kunci ini harus cocok dari yang diberikan akses point ke client, dengan yang dimasukkan client untuk otentikasi menuju access point.

\section{RANCANGAN SISTEM}

\section{Kebutuhan Perangkat Keras (Minimal)}

1. Motherboard x86 $300 \mathrm{MHZ}$ Pentium

2. RAM $64 \mathrm{MB}$

3. Hardisk $40 \mathrm{~GB}$
Kebutuhan hardware untuk menginstal Router OS, dalam hal ini menggunakan MikrotikOS

1. CPU dan motherboard $100 \mathrm{MHz}$ Pentium.

2. RAM $32 \mathrm{MB}$

3. Hardisk ATA/IDE 1 GB.

\section{Kebutuhan Perangkat Lunak}

Media instalasi Linux Ubuntu dan MikroTik adalah:

- CD Linux Ubuntu Server 8.04 LTS

- CD MikroTik

- Software FreeRADIUS Server

- Software LAMP (Linux Apache MySql Php)

\section{Kebutuhan Pengguna}

Pada dasarnya, Pengguna melihat bahwa jarringan yang diperlukan cukup sederhana dan tidak rumit. Ini dikarenakan client memandang jaringan hanya digunakan untuk share informasi yang umum dan koneksi internet.

Berikut ini adalah ringkasan dari kebutuhan pengguna dilihat dari beberapa parameter. Ringkasan ini didapatkan dari pemegang kebijakan kampus terhadap pengembangan jaringan:

Tabel 1. Kebutuhan Pengguna

\begin{tabular}{ll}
\hline Parameter & Kebutuhan Pengguna \\
\hline $\begin{array}{l}\text { Waktu Akses Staf } \\
\text { Waktu Akses }\end{array}$ & $\begin{array}{l}\text { Jam kerja }(08.00-15.00) \\
\text { Mahasiswa }\end{array}$ \\
$\begin{array}{l}\text { Waktu Respon } \\
\text { Realibilitas Tampilan }(07.00-21.00)\end{array}$ & $\begin{array}{l}\text { 5 Menit } \\
\text { Sistem selalu di- maintenance oleh } \\
\text { administrator WEB Base }\end{array}$ \\
Keamanan & $\begin{array}{l}\text { Jaminan keamanan pengguna dan } \\
\text { device } \\
\text { Aplikasi mudah digunakan oleh } \\
\text { pengguna }\end{array}$ \\
\hline
\end{tabular}

\section{Analisa Aplikasi}

Aplikasi yang ada di jaringan Universitas Kanjuruhan Malang dibedakan menjadi beberapa kategori yaitu:

\section{Aplikasi Desktop}

Aplikasi Desktop adalah suatu aplikasi yang dapat berjalan sendiri atau independen tanpa menggunakan browser pada suatu komputer otonom dengan sistem operasi tertentu. Penggunaan aplikasi desktop dengan cara meng-install aplikasi ini pada masing-masing pengguna.

Penggunaan aplikasi desktop di Universitas Kanjuruhan Malang adalah untuk proses administrasi 
pada jaringan lokal. Beberapa aplikasi desktop diantaranya adalah bits dosen, bits mahasiswa dan bits akademik. Semua aplikasi tersebut bekerja sebagai client server.

\section{Aplikasi WEB}

Beberapa aplikasi berbasis WEB yang ada di Universitas Kanjuruhan Malang adalah elearning, ebook, ejournal, WEB mail client, perpustakaan on line, SIAKAD yang bisa diakses baik melalui jaringan lokal maupun jaringan internet.

\section{Aplikasi Server}

Beberapa aplikasi server yang digunakan di Universitas Kanjuruhan Malang adalah WEB server, database server, mail server, FTP server, DNS server, proxy server dan firewall.

\section{$\underline{\text { Akses Pengguna }}$}

Dari pemaparan diatas dapat digambarkan seperti pada Gambar 4 dimana dosen, staf dan laboratorium dapat mengakses aplikasi desktop dan aplikasi WEB, sedangkan hostspot hanya mengakses aplikasi WEB saja.

\section{Perancangan Sistem}

Perancangan sistem otentikasi pengguna jarringan di Universitas Kanjuruhan Malang memanfaatkan protokol RADIUS dan protokol TCP/IP (Transfer Control Protocol/ Internet Protocol). Untuk dapat

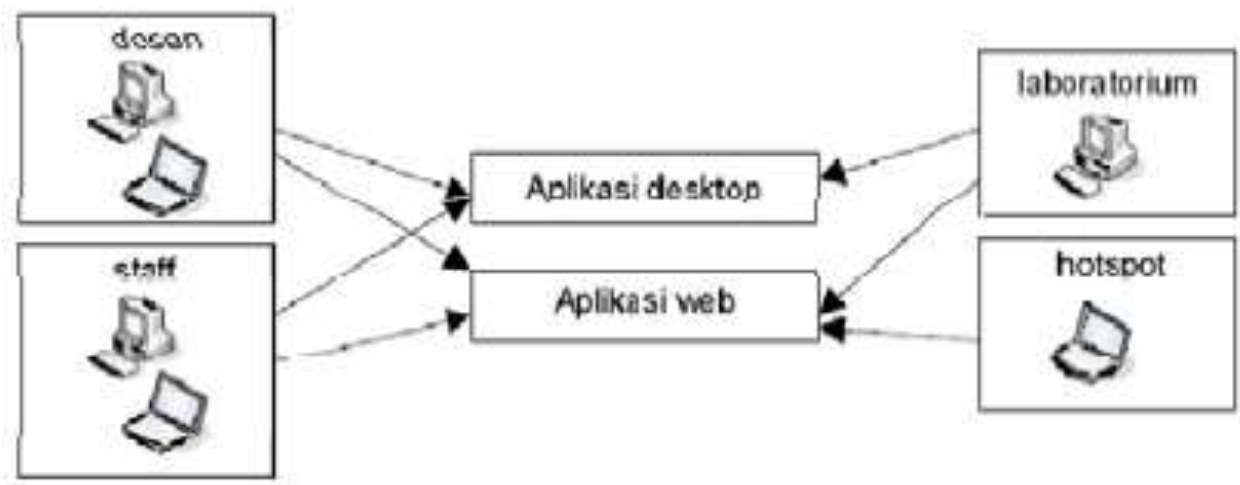

Gambar 4. Akses Pengguna

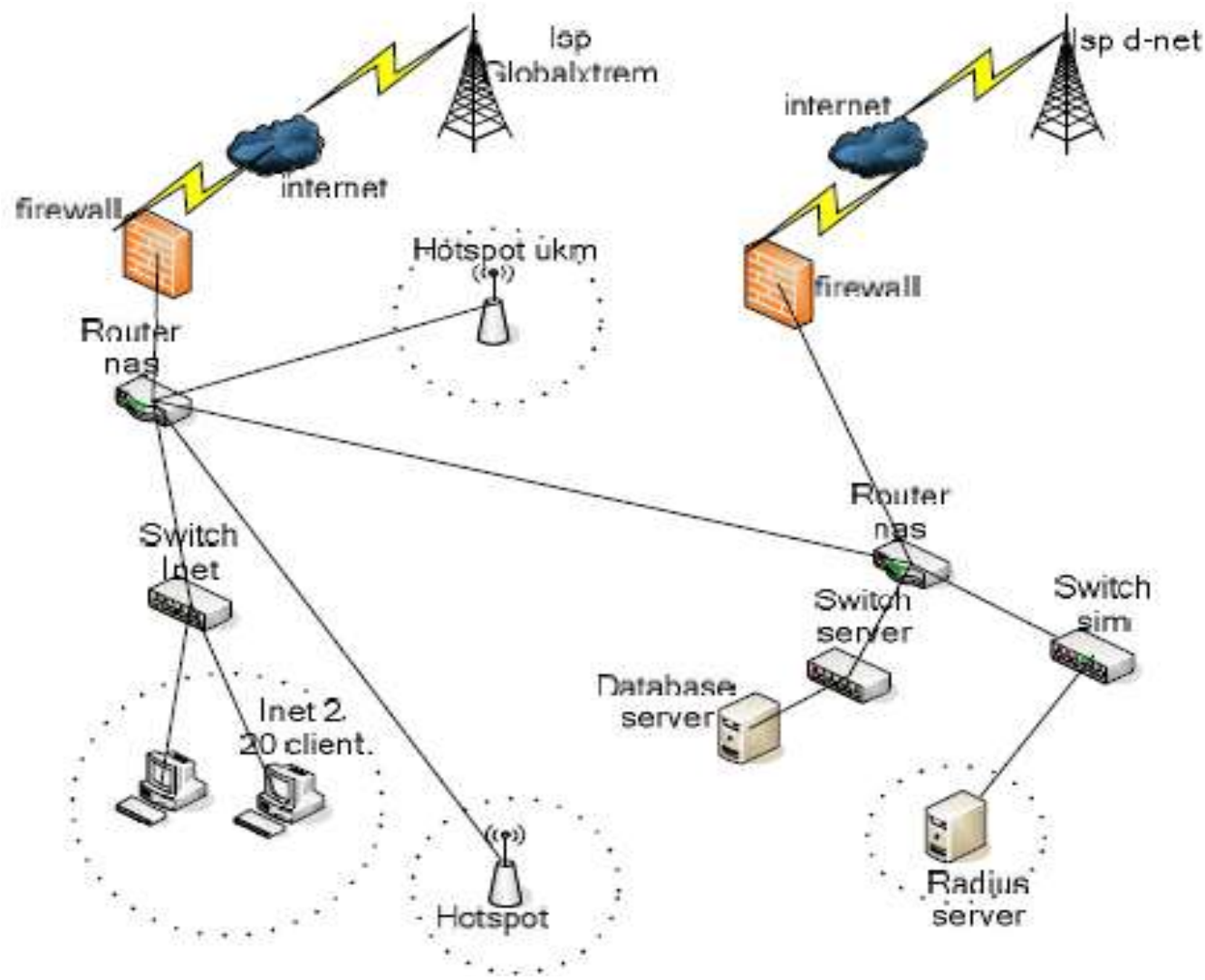

Gambar 5. Desain Topologi RADIUS 
terhubung ke dalam jaringan pengguna harus memasukan username dan password.

\section{$\underline{\text { Topologi Jaringan }}$}

Pada saat ini, jaringan Universitas Kanjuruhan Malang digunakan untuk administrasi dan akses internet, sebagaimana ditampilkan dalam Gambar 4. Jaringan Universitas Kanjuruhan menggunakan media transmisi kabel dan nirkabel. Untuk menghubungkan antar gedung kabel yang digunakan adalah kabel STP (Shield Twister Pair). Untuk menghubungkan client dalam satu ruangan digunakan media transmisi kabel UTP (Unshield Twister Pair) dan wireless. Sedangkan media transmisi untuk hostspot area bagi mahasiswa digunakan wireless.

Untuk memecah antar client digunakan HUB yang diletakan ditiap gedung atau ruangan disesuaikan dengan jumlah client.

\section{Desain Topologi RADIUS}

Secara sederhana desain topologi dengan RADIUS Server seperti pada Gambar 5. Server RADIUS berfungsi menyimpan username dan password secara terpusat. Pengguna memasukan username dan password melalui interface yang disediakan oleh NAS (Network Access Server), selanjutnya NAS akan menanyakan ke RADIUS server apakah username dan password ada dalam database. Jika username dan password ada maka pengguna akan diijinkan menggunakan jaringan.

\section{Arsitektur Sistem}

Arsitektur Pengambilan Data Pengguna Arsitektur pengambilan data pengguna dari database akademik ke dalam RADIUS Server seperti terlihat pada gambar dibawah ini.

Gambar 6 menggambarkan arsitektur pengambilan data pengguna dari database akademik ke dalam RADIUS server. Administrator mengambil data pengguna dari Database Server untuk dimasukan ke RADIUS Server. Data yang diambil adalah data mahasiswa yang telah registrasi pada semester berjalan. Data yang dimasukkan ke RADIUS Server adalah NIM (Nomor Induk Mahasiswa), password, nama dan program studi.

\section{Arsitektur Sistem Otentikasi}

Arsitektur sistem otentikasi seperti terlihat pada Gambar 7. Gambar 7 menggambarkan arsitektur sistem otentikasi, terlihat bahwa pengguna terdiri dari dosen, staf dan mahasiswa. Pengguna agar terhubung ke dalam jaringan harus menggunkan PC atau Laptop. Pengguna dapat memanfaatkan jaringan apabila memiliki username dan password pada RADIUS server. Apabila pengguna sudah berhasil login, maka pengguna bisa terhubung jaringan. Username dan password yang digunakan untuk login adalah user dan password yang digunakan untuk login pada aplikasi bits mahasiswa.

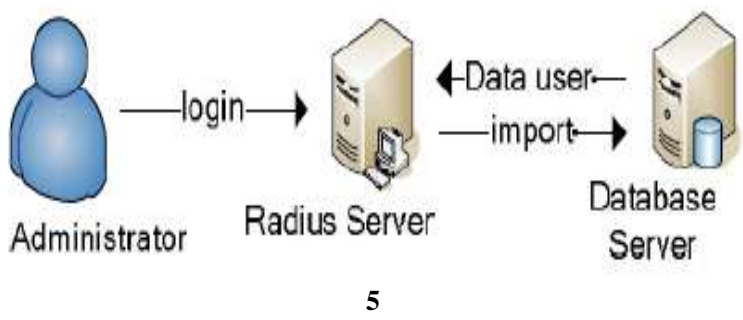

Gambar 6. Arsitektur pengambilan data pengguna

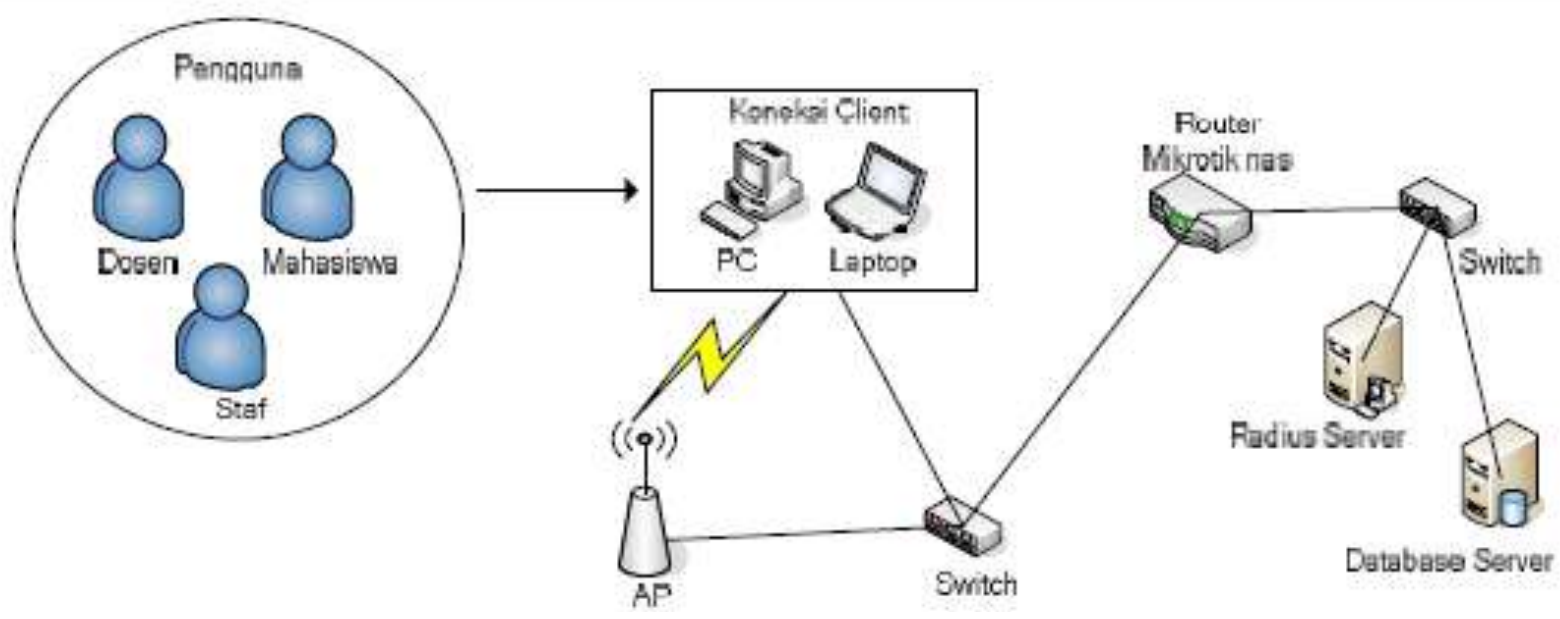

Gambar 7. Arsitektur Sistem Otentikasi 


\section{PENGUJIAN PENELITIAN}

\section{Pengujian Hasil Tool Importer Pengguna}

Tabel 2. Pengujian hasil importer

\begin{tabular}{|c|c|c|c|}
\hline $\begin{array}{l}\text { Test ID } \\
\text { Tujuan Test } \\
\text { Kondisi Awal } \\
\end{array}$ & & \multicolumn{2}{|c|}{$\begin{array}{l}\text { Mengetahui hasil tool importer } \\
\text { Data belum ter import }\end{array}$} \\
\hline Prosedur pengujian & Hasuil yang diharapkan & Hasil yang diperoleh & Kesimpulan \\
\hline \multicolumn{4}{|c|}{ Data berhasil di import } \\
\hline $\begin{array}{l}\text { - } \text { Masuk ke server Radius } \\
\text { - Gunakan mysql client, ketik mysql -u user -p } \\
\text { - Masukkan quary untuk mengecek data sudah } \\
\text { masuk atau belum } \\
\text { - } \text { Query: Select* from radchehk where } \\
\text { usename like } * 040403 \% \\
\end{array}$ & $\begin{array}{l}\text { Pada database radius table } \\
\text { redcheck berisi data } \\
\text { pengguna yang diambil } \\
\text { menggunakan importer }\end{array}$ & $\begin{array}{l}\text { Data masuk ke database } \\
\text { Radius table radcheck }\end{array}$ & $\begin{array}{l}\text { Tool importer berjalan } \\
\text { sesuai dengan } \\
\text { rancangan }\end{array}$ \\
\hline
\end{tabular}

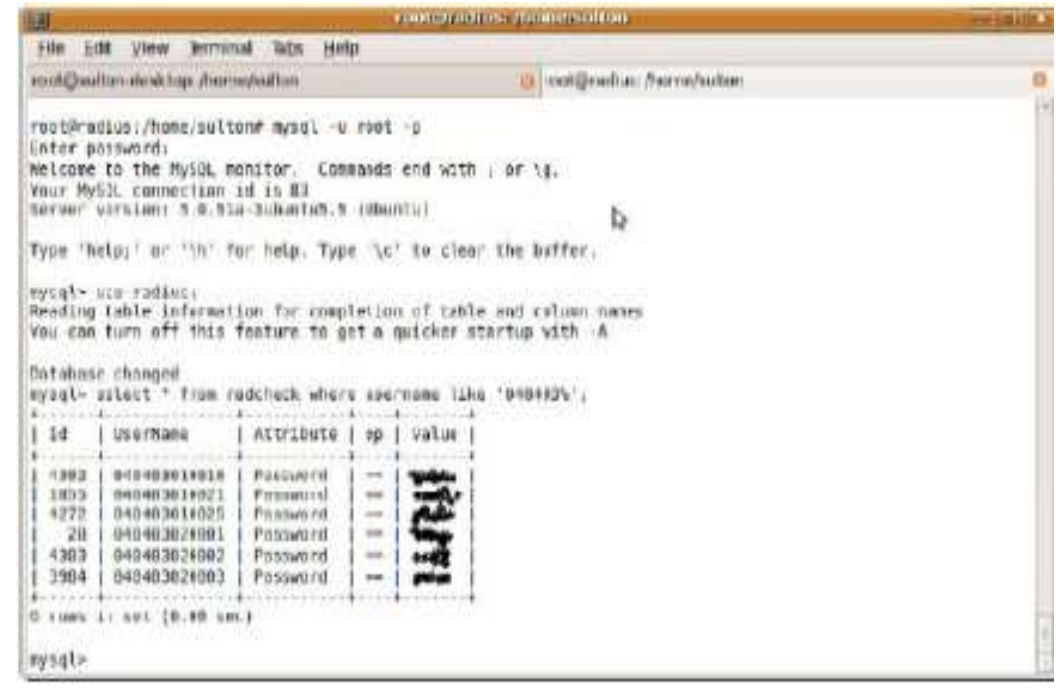

Gambar 8. RedCheck

\section{Pengujian Pengguna}

Tabel 3. Pengujian Pengguna

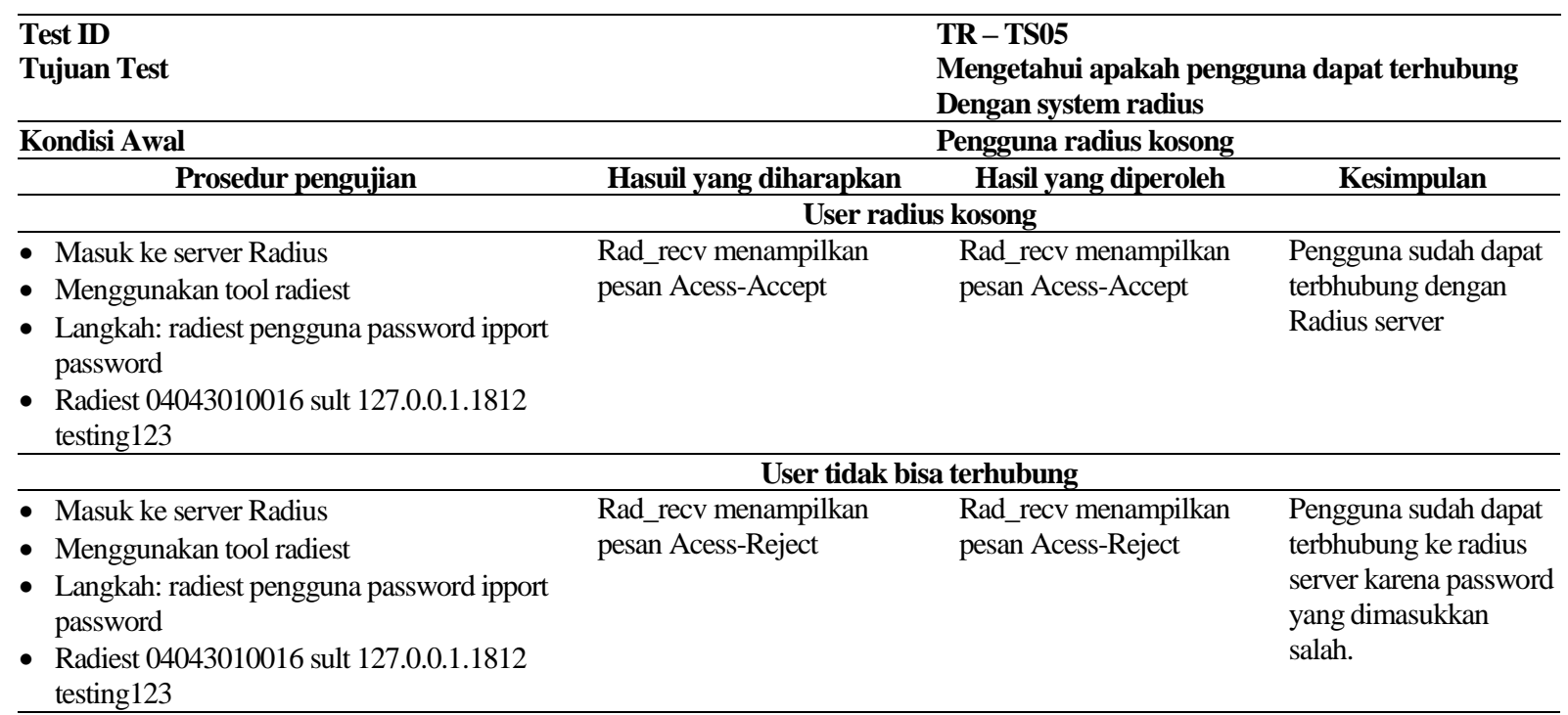




\section{Pengujian Mikrotik Hotspot User}

Tabel 4. Pengujian Mikrotik hotspot user

\begin{tabular}{|c|c|c|c|}
\hline $\begin{array}{l}\text { Test ID } \\
\text { Tujuan Test } \\
\text { Kondisi Awal }\end{array}$ & & $\begin{array}{l}\text { TR-TS03 } \\
\text { Mengetahui fungsi user I } \\
\text { User tidak ada }\end{array}$ & Mikrotik NAS \\
\hline Prosedur pengujian & Hasuil yang diharapkan & Hasil yang diperoleh & Kesimpulan \\
\hline \multicolumn{4}{|c|}{ User disable pada Mikrotik } \\
\hline $\begin{array}{l}\text { - Login ke Mikrotik dengan winbox } \\
\text { - Masuk menu ip hotspot user } \\
\text { - Disable semua user yang ada }\end{array}$ & User cepat melakukan login & $\begin{array}{l}\text { User dapat melakukan } \\
\text { login }\end{array}$ & $\begin{array}{l}\text { Komunikasi Mikrotik } \\
\text { NAS berjalan dengan } \\
\text { normal }\end{array}$ \\
\hline \multicolumn{4}{|c|}{ User Aktif pada Mikrotik NAS } \\
\hline $\begin{array}{l}\text { - Login ke Mikrotik dengan winbox } \\
\text { - Masuk menu ip hotspot user } \\
\text { - Perhatikan user yang ada }\end{array}$ & $\begin{array}{l}\text { List pengguna muncul pada } \\
\text { tab active }\end{array}$ & $\begin{array}{l}\text { List pengguna muncul } \\
\text { pada tab active }\end{array}$ & $\begin{array}{l}\text { Komunikasi NAS } \\
\text { berjalan normal } \\
\text { sehingga pengguna dari } \\
\text { radius server muncul } \\
\text { pada list active }\end{array}$ \\
\hline
\end{tabular}

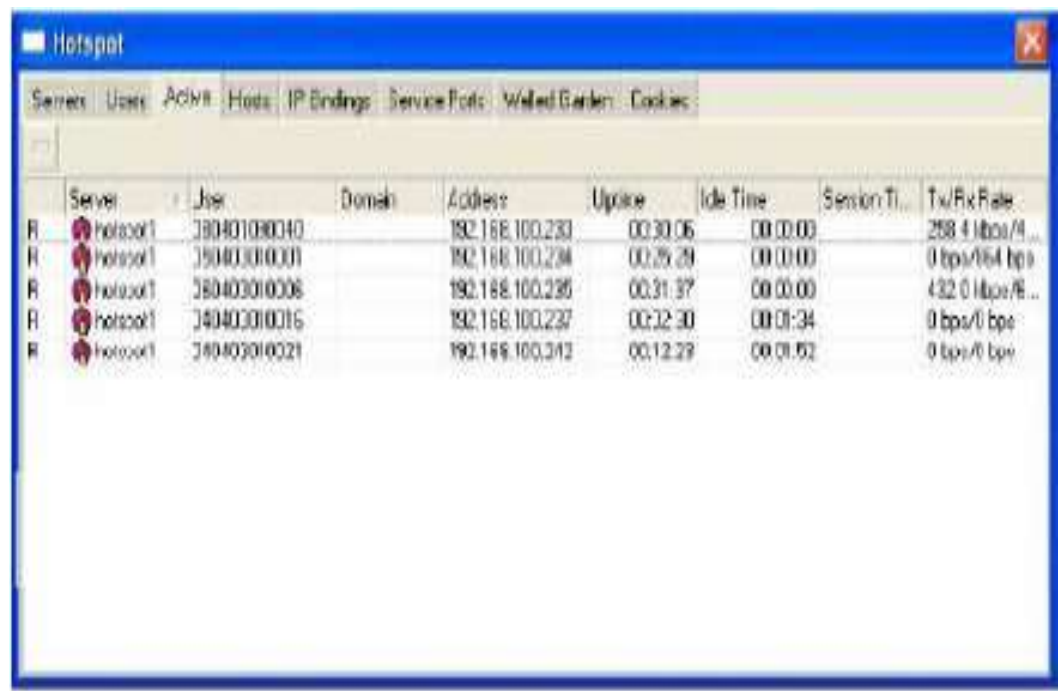

Gambar 9. User aktif pengguna jaringan

\section{Pengujian Interface Login}

Tabel 5. Pengujian interface login

\begin{tabular}{|c|c|c|c|}
\hline $\begin{array}{l}\text { Test ID } \\
\text { Tujuan Test } \\
\text { Kondisi Awal } \\
\end{array}$ & & $\begin{array}{l}\text { TR - TS02 } \\
\text { Menguji login hotspot } \\
\text { Membuka web brower }\end{array}$ & \\
\hline Prosedur pengujian & Hasuil yang diharapkan & Hasil yang diperoleh & Kesimpulan \\
\hline \multicolumn{4}{|c|}{ Login Sukses } \\
\hline $\begin{array}{l}\text { - } \text { Buka browser } \\
\text { - Masukkan alamat web } \\
\text { - Misal: google.co.id } \\
\text { - Akan dipaksa masuk ke login hotspot }\end{array}$ & $\begin{array}{l}\text { Sebelum sukses login akan } \\
\text { di redirect ke halaman login }\end{array}$ & $\begin{array}{l}\text { Client di redirect ke } \\
\text { halaman login }\end{array}$ & $\begin{array}{l}\text { Client belum } \\
\text { melakukan login }\end{array}$ \\
\hline $\begin{array}{ll}\text { - } & \text { Buka browser } \\
\text { - } & \text { Masukkan alamat web }\end{array}$ & $\begin{array}{l}\text { Clien berhasil login dan } \\
\text { masuk ke halaman login }\end{array}$ & $\begin{array}{l}\text { Client di redirect ke } \\
\text { halaman login }\end{array}$ & $\begin{array}{l}\text { Client belum } \\
\text { melakukan login }\end{array}$ \\
\hline \multicolumn{4}{|c|}{ Login Gagal } \\
\hline $\begin{array}{l}\text { - } \text { Buka browser } \\
\text { - Masukkan alamat web } \\
\text { - Misal: google.co.id } \\
\text { - Akan dipaksa masuk ke login hotspot } \\
\text { - Masukkan usename dan password } \\
\text { - User: } 040403017 \text { password: sult }\end{array}$ & $\begin{array}{l}\text { Mendapat pesan username } \\
\text { atau password salah, pastikan } \\
\text { anda sudah registrasi di bau } \\
\text { atau hubungi staf sim Univ. } \\
\text { Kanjuruan Malang }\end{array}$ & $\begin{array}{l}\text { Client gagal masuk ke } \\
\text { halaman google.co.id }\end{array}$ & $\begin{array}{l}\text { Ada kesalahan pada } \\
\text { imput username atau } \\
\text { password }\end{array}$ \\
\hline $\begin{array}{l}\text { - Pergunakan } 2 \text { komputer } \\
\text { - } \text { Login dengan user yang sama }\end{array}$ & $\begin{array}{l}\text { Mendapatkan pesan bahwa } \\
\text { user sedang aktif }\end{array}$ & $\begin{array}{l}\text { Mendapat pesan bahwa } \\
\text { pengguna sedang aktif }\end{array}$ & $\begin{array}{l}\text { Login ganda tidak } \\
\text { diijinkan }\end{array}$ \\
\hline
\end{tabular}




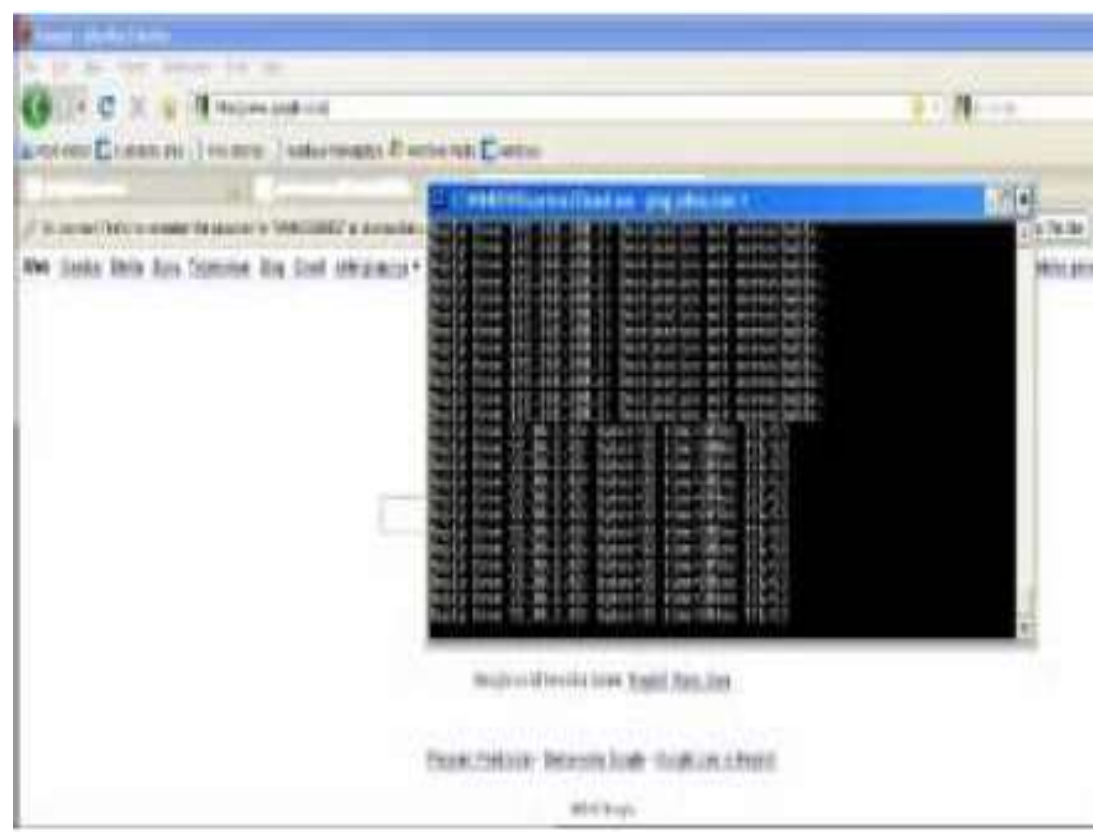

Gambar 10. Uji coba Login Sukses

\section{KESIMPULAN}

Berdasarkan pengujian dan implementasi sistem yang telah dilakukan, dapat disimpulkan bahwa dengan menggunakan RADIUS dengan software free RADIUS yang dihubungkan dengan Mikrotik sebagai network access server dapat digunakan untuk otentikasi pengguna pada jaringan Universitas Kanjuruhan Malang. Dengan adanya otentikasi user ini diharapkan dapat meningkatkan keamanan jaringan komputer.

\section{DAFTAR PUSTAKA}

1. Arifin, Zaenal. 2008. Sistem Pengamanan Jaringan Wireless LAN Berbasis Protokol 8.02.1x dan Sertfikat. Penerbit Andi. Yogyakarta.

2. Febyatmoko, dkk. 2006. Otentikasi, Otorisasi \& Pelaporan Koneksi User Wireless Chillispot dan
Server RADIUS. http://journal.uii.ac.id/index.php/ mediainformat ika/ article/viewFile/122/83 (akses 20 januari 2010).

3. Kelompok 123P IKI-83408T MTI UI. 2005. Keamanan Jaringan Komputer. http://bebas.vlsm. org/v06/Kuliah/MTIKeamananSistem-Informasi/ 2005/123/123P-03-final1.0-network_security.pdf (akses 20 januari 2010).

4. Linto, Herlambang Moch., dan Catur L. Azis. 2008. Panduan Lengkap Menguasai Router Masa Depan Menggunakan Mikrotik RouterOSTM. Penerbit Andi. Yogyakarta.

5. Rigney, et al. 2000. Remote Authentication Dial In User Service (RADIUS). http://www.ietf.org/rfc/ rfc2865.txt (akses 19 januari 2010).

6. Wagito. 2007. Jaringan Komputer Teori dan Implementasi Berbasis Linux. Gava Media. Yogyakarta. 